\title{
A Psicologia Discursiva nos estudos em Psicologia Social e Saúde
}

\section{Discursive Psychology in Social Psychology and Health studies}

\author{
Emerson F. Rasera* \\ Universidade Federal de Uberlândia - UFU, Uberlândia, Minas Gerais, Brasil
}

\begin{abstract}
RESUMO
A Psicologia Discursiva tem ganhado destaque na Psicologia Social nos últimos anos, propondo novos objetos e métodos de investigação. Este artigo tem por objetivo apresentar os principais pressupostos teóricometodológicos da Psicologia Discursiva e refletir sobre as tendências e os desafios de sua utilização no campo dos estudos em Psicologia Social e Saúde. A Psicologia Discursiva é descrita a partir de suas influências pela Análise da Conversação, Retórica e Filosofia da linguagem, sendo apresentado o Modelo da Ação Discursiva e as etapas da Análise do Discurso. No campo dos estudos em Psicologia Social e Saúde, são descritas duas tendências: uma que privilegia o estudo dos repertórios interpretativos e outra voltada à construção discursiva do processo saúde-doença-cuidado. Os principais desafios identificados para a utilização desse referencial teórico-metodológico nesse campo de estudos se referem à hegemonia do discurso biomédico na saúde, às tradições realistas de pesquisa e à lógica tecnicista no cuidado em saúde.
\end{abstract}

Palavras-chave: Psicologia Discursiva, Análise do Discurso, Psicologia Social, Saúde.

\begin{abstract}
Discursive Psychology has gained prominence in Social Psychology in recent years, proposing new objects and methods of inquiry. This article aims to present the main theoretical and methodological assumptions of Discursive Psychology and to analyze the trends and challenges of its use in the field of Social Psychology and Health. Discursive Psychology is described based on the influences of Conversation Analysis, Rhetoric and the Philosophy of Language, and it is presented the Model of Discursive Action and the stages of Discourse Analysis. In the field of Social Psychology and Health, it is described two trends: one that promotes the study of the interpretative repertoires and another one interested on the discursive construction of the health-illness-care process. The main challenges identified in this field are the hegemony of biomedical discourse, the realist traditions of research, and the technicist logic in healthcare.
\end{abstract}

Keywords: Discursive Psychology, Discourse Analysis, Social Psychology, Health. 


\section{I ntrodução}

A Psicologia Discursiva tem consistido em uma forma de inteligibilidade em Psicologia Social que tem ganhado destaque nos últimos anos, propondo novos objetos e métodos de investigação. Apesar de sua crescente produção na literatura psi internacional, ela ainda não é tão difundida no contexto brasileiro. Buscando contribuir com o seu debate, este artigo tem por objetivo apresentar os principais pressupostos teórico-metodológicos da Psicologia Discursiva e refletir sobre os usos e os desafios de sua utilização no campo dos estudos em Psicologia Social e Saúde.

\section{A Psicologia Discursiva: suas origens, influências e propostas}

O livro "Discourse and Social Psychology" é um marco significativo na história da construção da Psicologia Discursiva. Publicado em 1987, por Jonathan Potter e Margareth Wetherell, da Universidade de Loughborough/Inglaterra, propunha a Análise do Discurso como uma forma de pesquisar em Psicologia Social para além das atitudes e comportamentos, defendendo o estudo do discurso como um tópico de interesse e enfatizando os aspectos construtivos e ativos do uso da linguagem na vida cotidiana.

Cinco anos após, Derek Edwards e Jonathan Potter publicam "Discursive Psychology", consagrando essa denominação para a proposta teórico-metodológica por eles defendida. Neste livro, os autores revêem criticamente as pesquisas de memória e atribuição, como representantes de perspectivas cognitivas e sócio-cognitivas, e apresentam o Modelo de Ação Discursiva, que sintetiza os principais pressupostos da Psicologia Discursiva.

Outros autores do "Discourse and Rethoric Group" daquela Universidade (Antaki, Billig, Cromby, Edley, Middleton, Wilkinson, Kitzinger) dão continuidade a tal empreitada, desenvolvendo uma série de pesquisas que permitiram rever conceitos como atitude e crença, categorização, memória conversacional, emoção, entre outros.

De forma geral, a Psicologia Discursiva se situa em uma epistemologia construcionista (GERGEN, 1997), a qual enfatiza o duplo caráter de construção da linguagem, ou seja, como construída historicamente e como construtora de realidades. Nos dizeres de Potter, trata-se de uma opção pragmática pelo construcionismo: “A realidade adentra as práticas humanas pelas categorias e descrições que são parte daquelas práticas (...). Ela [a realidade] é constituída de uma forma ou outra à medida que as pessoas conversam, escrevem e discutem sobre ela" (POTTER, 2000, p. 98). 
A Psicologia Discursiva teve diferentes influências em sua construção (POTTER, WETHERELL, 1987; POTTER, 1996; EDWARDS, 2004), entre as quais podemos destacar: a Análise Conversacional, a Retórica e a Filosofia da linguagem. A Análise Conversacional contribuiu com uma forma minuciosa e empiricamente orientada para a análise das práticas conversacionais, mais especificamente, o modo pelo qual a linguagem constitui uma ação. Assim, ao invés de focar a análise nas visões, percepções, e atitudes implícitas na fala dos entrevistados, a Análise da Conversação as compreende como tentativas de produzir versões factuais dos acontecimentos, de apresentar a própria identidade de modo preferível, entre outras ações possíveis. A Retórica, por outro lado, ofereceu um princípio teórico e metodológico que incentiva o pesquisador a buscar versões alternativas ou opostas da descrição de determinada pessoa ou situação, e a reconhecer as antecipações e os endereçamentos presentes nos atos discursivos, de forma a ampliar o entendimento do que é dito/escrito. Na Psicologia Discursiva, a retórica é analisada nas conversas cotidianas e não apenas nos textos claramente persuasivos ou nos discursos políticos. A Filosofia da linguagem, especialmente pelas contribuições de Wittgenstein e Austin, chamou a atenção que o significado das palavras está em seu uso, mais do que em um suposto objeto de referência. Trata-se de uma atenção às ações e aos mundos criados por determinados vocabulários que, na prática da Psicologia Discursiva, se baseia na análise de materiais empíricos, ao invés de estudos filosóficos e conceituais.

Considerando estas contribuições, a Psicologia Discursiva busca compreender como o discurso realiza práticas sociais, sem se restringir à estrutura linguística ou às cognições subjacentes à conversa. Nesse sentido, as conversas e os textos são entendidos como partes de práticas sociais. Entre os principais tipos de investigação promovidos pela Psicologia Discursiva estão: releituras de conceitos comuns da psicologia como práticas de discurso, estudos sobre o discurso psicológico do senso comum, e sobre o modo de manejo de questões psicológicas, tais como responsabilidade e motivação (EDWARDS, 2004). Tipicamente, se redimensionam conceitos cognitivos, estudando-os como ação situada em um contexto discursivo e retórico. Seu objetivo não é negar as formas de organização cognitiva, mas questionar alguns pressupostos e procedimentos pelas quais as cognições são definidas.

Em uma perspectiva abrangente, a Psicologia Discursiva se estruturaria, segundo alguns autores (HEPBURN, WIGGINS, 2007; WIGGINS, POTTER, 2008), a partir de três princípios básicos: 1) orientação para ação, pelo qual se compreende que toda fala realiza uma ação; 2) situação, entendida como: a) sequencialidade, ou seja, que o sentido do que se diz se dá pelo que o antecede e o segue; b) institucionalidade, que reconhece que o discurso é marcado por 
determinadas identidades e tarefas institucionais; c) retoricalidade, pelo qual o sentido está inserido em um jogo de resistência em relação a versões alternativas; e 3) construção, pelo qual o discurso é tido como construído por uma variedade de recursos linguisticos e construtor de diferentes versões de mundo.

Esses princípios gerais podem ser encontrados, e melhor compreendidos, em um modelo muito difundido nessa literatura, o Modelo da Ação Discursiva, proposto por Edwards e Potter (1992). Esse modelo descreve o funcionamento do discurso a partir de alguns aspectos: Ação, Fato e Interesse, e Responsabilidade (Accountability).

A Ação consiste no aspecto fundamental da Psicologia Discursiva, à medida que ela está interessada nas práticas discursivas das pessoas e em sua organização em diferentes tipos de contextos. O foco está na ação e não na cognição ou qualquer outra entidade psicológica interna ao sujeito. Da mesma forma, o discurso é o objeto de estudo em si, e não sua capacidade de espelhar ou dar acesso a outra realidade. Assim, o estudo situado do discurso sustenta uma visão da linguagem como ação, relegando a uma posição subordinada a da linguagem como representação (da cognição ou da realidade). Segundo Edwards e Potter (1992), o objeto da Psicologia Discursiva é a "natureza da ação discursiva como parte de uma sequência de atividade" (p. 156), tais como aquelas envolvendo a recusa de convites, a culpabilização e as defesas.

O Fato e o Interesse se referem ao interesse dos participantes na construção discursiva dos fatos, que sempre sustentam determinadas opções sem, muitas vezes, parecer fazê-lo. Neste sentido, os relatos fatuais não são simples descrições neutras que correspondem a uma realidade dada, mas consistem de realizações sociais pelas quais as descrições fatuais são construídas como tais por meio de diferentes recursos discursivos.

Segundo Potter (2000), estes recursos de construção dos fatos podem ser: a descrição vívida e detalhada, que cria a impressão de uma visão real da situação descrita; a imprecisão sistemática, que dificulta a crítica ao mesmo tempo em que oferece elementos básicos para permitir certa inferência; a descrição empiricista, que considera os fenômenos como ativos e as pessoas como recipientes passivos forçados à determinada situação; a formulação de casos extremos, tal como em "todo mundo faz isso", pela qual se tornam determinadas ações comuns; o uso de argumentos baseados na lógica e em silogismos, de forma a construir um senso de racionalidade; entre outras. Esses recursos são utilizados de forma retórica, buscando sustentar determinadas versões e minar versões alternativas, sem parecer fazê-lo. Seu uso é amplamente difundido em nossa sociedade, não se restringindo a situações de conflito ou debate. 
A Responsabilidade está relacionada à responsabilidade do falante/escritor pelo relato e suas consequências. A construção da responsabilidade dos atores e eventos de um relato ocorre de forma a definir a responsabilidade do falante/escritor e vice-versa. Este é um aspecto importante desse modelo à medida que em muitas situações cotidianas os eventos que relatamos são aqueles dos quais participamos e temos interesses específicos e nos quais nossa responsabilidade está em jogo. Esta responsabilidade é relativamente formalizada nas controvérsias políticas e no sistema judiciário, porém é mais informal nas conversas cotidianas, nas fofocas, e nas disputas corriqueiras.

É importante destacar que esse modelo não é a base para uma psicologia individual, seja porque o falante não é considerado como controlando individualmente a conversa ou o texto, que são tomados como sendo sempre um produto colaborativo e coletivo, seja porque os agentes construídos nas conversas são de diferentes tipos, podendo ser atores, partes desses atores ou coletivos (POTTER, WETHERELL, 1987).

\section{A Psicologia Discursiva e a Análise do Discurso}

A Psicologia Discursiva propõe como metodologia a Análise do Discurso. Este não é um método no sentido de um conjunto de procedimentos sequenciais bem estabelecidos a serem seguidos cujo resultado final é o conhecimento verdadeiro sobre o fenômeno estudado. O que se propõe é um arcabouço teórico relativo à natureza da linguagem e seu papel na vida social, bem como um conjunto de sugestões e cuidados sobre como ele pode ser estudado (ANTAKI et al., 2003).

O campo da Análise do Discurso é complexo, envolvendo diferentes perspectivas tais como a Teoria dos Atos de Fala, a Sociolinguística Interacional, a Etnografia da Comunicação, a Pragmática, a Análise da Conversação, entre outras (INIGUEZ, 2004; NOGUEIRA, 2008; SCHIFFRIN, 1994). A perspectiva apresentada neste artigo está associada a uma corrente anglo-saxã de Análise do Discurso constituída por autores identificados com a Psicologia Discursiva.

Nessa proposta teórico-metodológica, a linguagem é considerada em três aspectos distintivos: função, variação e construção (POTTER, WETHERELL, 1987). A função se refere ao fato das pessoas usarem a linguagem para fazerem coisas, tais como, solicitar, reclamar, persuadir, e acusar. Toda linguagem, mesmo a aparentemente descritiva, é sempre construtiva e constitui uma ação. Esta ação não é decorrente apenas da seleção e organização das palavras, mas depende também do contexto no qual é realizada. Dado que uma conversa pode se orientar para diferentes funções, as descrições e 
relatos de uma pessoa podem ter uma variação considerável nas situações. Uma descrição pode variar e ganhar detalhes e nuances diferenciadas conforme o propósito da conversa e os interlocutores presentes. A estabilidade e consistência dos relatos identificados por outras perspectivas em Psicologia são reexaminadas, não se referindo a constructos psicológicos internos, mas à semelhança da função que desempenham na interação. Em relação à construção, esta se relaciona à ideia de que as descrições dos eventos são realizadas por meio de recursos linguísticos pré-existentes, os quais são ativamente selecionados pelo falante, no processo de definição da situação. Concluindo, a função da linguagem envolve a construção de versões do mundo social a qual é demonstrada pela variação da linguagem.

Este entendimento sobre a linguagem orienta uma prática analítica, um modo de produzir interpretações a partir do discurso considerado. Visando este objetivo, Potter e Wetherell (1987) descrevem dez etapas na análise do discurso, que não devem ser consideradas sequenciais, mas como uma forma didática de compreender as várias questões e tarefas comuns ao trabalho de análise. Apesar de trabalhos posteriores aprofundarem a discussão sobre aspectos do processo analítico (ANTAKI et al., 2003), tais etapas ainda resumem de forma pertinente um conjunto de cuidados e decisões a serem tomados pelo pesquisador.

A etapa um se refere às questões de pesquisa, as quais devem estar relacionadas ao discurso, sua construção e função, ou seja, a como o discurso está organizado e o que ele realiza na vida social. O discurso não deve ser entendido como um canal transparente de informação, nem como um meio de acesso a realidades mentais. Assim, as questões de pesquisa estão diretamente vinculadas ao arcabouço teórico da Psicologia Discursiva, não sendo possível utilizar sua metodologia de forma a responder a qualquer tipo de interesse ou problema científico.

A seleção do material é a etapa dois. Na análise do discurso, o tamanho do material analisado depende da questão da pesquisa. Ela pode consistir de um único texto, de um caso incomum, de muitas entrevistas ou, tipicamente, do que for disponível. O importante é considerar que não há um conjunto de textos que possa ser considerado completo. Trata-se, portanto, de explicitar detalhadamente a natureza do material analisado.

A etapa três é a coleta de registros e documentos. Os analistas do discurso trabalham, frequentemente, com materiais não produzidos por eles (transcrições de conversas cotidianas, documentos oficiais, relatórios, notícias de jornais) e que permitem uma maior variedade de relatos e descrições, bem como, facilitam a análise da natureza construída do discurso, dado o interjogo das relações sociais, seus conflitos e nuances. 
A despeito das vantagens dos registros cotidianos, as entrevistas consideradas a etapa quatro - também consistem uma fonte possível para os analistas do discurso. Contudo, elas devem ser realizadas por meio de trocas conversacionais mais informais, gerando uma diversidade de práticas discursivas. Assim, estimular novos contextos interpretativos, tais como aqueles gerados pela inserção de um mesmo tema em diferentes momentos da entrevista, facilita compreender a função das construções dos entrevistados. Considerando a entrevista um encontro conversacional, na análise do discurso, as perguntas e intervenções do entrevistador devem ser ativa e criticamente analisadas.

A etapa cinco é constituída pela transcrição, entendida como uma atividade construtiva pautada em certas convenções. Há diferentes modelos de transcrição que podem ser considerados conforme o nível de análise a ser realizado. Contudo, é importante apontar que dada a influência da Análise da Conversação, e o foco nos detalhes da construção discursiva, muitos analistas utilizam transcrições que marcam as pausas, as hesitações, a entonação, e a sobreposição das falas.

A codificação é a etapa seis. Diferentemente de modos tradicionais de análise em Psicologia, a codificação na análise do discurso se refere a uma etapa preliminar da análise propriamente dita e que tem o objetivo pragmático de agregar grandes quantidades de dados baseado em categorias amplas e inclusivas relacionadas às questões da pesquisa. Por vezes, ela se dará de forma direta a partir de categorias claramente postas pelo objetivo da pesquisa. Em outras, uma codificação inicial do material permitirá uma análise que gera tentativas de interpretação teórica que permitem então especificar o fenômeno a ser analisado, em um processo cíclico de codificação e análise do material.

A etapa sete é constituída pela análise. Apesar de não haver uma receita para como fazer uma boa análise do discurso, esta envolve uma leitura intensiva e cuidadosa do material, na qual se considerem as nuances e os detalhes do discurso, e o que está dito ou escrito, ao invés de um olhar unificador ou uma ideia central homogeneizante. Deve-se evitar a leitura seletiva, a busca restritiva e a categorização grosseira. A análise envolve duas fases: a) a busca do padrão nos dados, seja pela análise do que é compartilhado (a consistência), seja pelas diferenças identificadas (a variabilidade) nos textos ou falas; e b) a análise das funções e efeitos dos discursos.

A validação das interpretações analíticas consiste a oitava etapa da análise do discurso. Ela se dá pela coerência das afirmações analíticas, pelo grau de orientação destas em relação às perspectivas dos participantes e pela capacidade de gerar novos problemas e novas explicações. 
A etapa nove se refere ao relato da pesquisa. Sua apresentação deve permitir ao leitor avaliar as interpretações do pesquisador. Assim, é importante inserir trechos do material, com detalhes da interpretação realizada e das afirmações analíticas produzidas. Além disso, a redação do relato da pesquisa deve ser concomitante à codificação e análise, pois as questões surgidas na escrita permitem que reflexivamente se desenvolva o processo de interpretação.

Finalizando as etapas da análise do discurso está a aplicação. O conhecimento produzido por meio da análise do discurso pode ser utilizado para promover uma atitude crítica em relação ao discurso, bem como uma consciência de sua natureza construída e seus efeitos políticos e sociais. Ele fornece condições para intervir na vida cotidiana, ao permitir questionar conceitos estabelecidos e identificar práticas opressoras, convidando a mudanças políticas e sociais (WIGGINS, HEPBURN, 2007).

Além dessa visão da linguagem e seu funcionamento, e das tarefas envolvidas na análise do discurso, é importante apresentar um conceito muito comum nas pesquisas em Psicologia Discursiva: o de repertório interpretativo. $\mathrm{Na}$ análise do discurso, este conceito propicia estudar os conteúdos sobre os quais se fala/escreve para, então, entender o seu uso em contextos específicos. Nas palavras de Potter e Wetherell (1995, p. 89):

\begin{abstract}
Repertórios interpretativos são claramente um modo de entendimento do conteúdo do discurso e da forma em que esse conteúdo é organizado. Apesar de elementos estilísticos e gramaticais estarem algumas vezes intimamente associados com esta organização, nosso foco analítico não é linguístico; ele se relaciona com o uso da linguagem, o que é alcançado por esse uso, e a natureza dos recursos interpretativos que permitem tal realização.
\end{abstract}

Os repertórios interpretativos são entendidos como blocos de construção, como passos numa dança, ou partes de uma colcha de retalhos, ou seja, são os elementos básicos utilizados no processo de construção. Cada repertório é constituído por um conjunto de termos, palavras chaves, imagens e metáforas, usado de modo gramatical e com estilo específicos. A partir da identificação dos repertórios interpretativos utilizados pelos falantes/escritores é possível reconhecer as suas funções e formas de uso nos contextos específicos (WETHERELL, POTTER, 1988).

Os repertórios interpretativos dialogam com o conceito de discurso. Apesar de ser uma diferenciação complexa, à medida que o próprio conceito de discurso contempla inúmeras definições, podemos apontar que, de modo geral, eles desempenham funções semelhantes. Se quisermos buscar uma distinção, ela diz respeito à vinculação a tradições analíticas diferentes. Assim, o termo discurso 
está usualmente ligado a perspectivas foucaultianas de análise que se interessam pelas relações de poder, estudando processos de assujeitamento, e consideram o discurso como construtor de instituições e sistema sociais. O termo repertório interpretativo, por sua vez, enfatiza a agência humana na construção de sentidos, entendendo as pessoas como usuárias dos discursos, e considerando esses conteúdos mais fragmentados e múltiplos, oferecendo várias possibilidades de significação. (BURR, 1995; EDLEY, 2001).

\section{Os estudos em Psicologia Social e Saúde: tendências e desafios}

As contribuições da Psicologia Discursiva e da Análise do Discurso a ela associada têm causado interesse por parte dos pesquisadores da área de Psicologia Social e Saúde nos últimos anos (HEPBURN, WIGGINS, 2007; MURRAY, CHAMBERLAIN, 1999; SARANGI, 2010). Essa apresentação não tem o objetivo de mapear sistematicamente a riqueza dos estudos nesta área, na literatura internacional, mas identificar temas e métodos comuns, tendências emergentes, bem como, alguns desafios presentes nas pesquisas em Psicologia Discursiva no campo da saúde. ${ }^{1}$

Em uma visão panorâmica da literatura, podemos identificar que tais pesquisas investigam diferentes aspectos do processo saúde-doença, desde aqueles relativos a práticas de promoção de saúde e "estilos de vida", bem como práticas de cuidado em saúde, tais como o manejo de dietas e o uso de medicação. Esses estudos ainda abarcam diferentes condições de saúde-adoecimento, tais como, câncer, depressão, distúrbios alimentares, diabetes, entre outros. Essa diversidade também é encontrada nos tipos de dados analisados, tais como transcrições de grupo focal, de entrevista, de conversa cotidiana, programas de rádio, artigos de jornal e revista e sites da internet.

Considerando esse olhar sobre a literatura da área, vemos que não há um conjunto de procedimentos claramente definidos a serem seguidos, e que as análise podem se dar de diferentes formas. Assim, inspirados pelas funções das pesquisas em Psicologia Discursiva (EDWARDS, 2004), realizamos uma análise da construção dos artigos em Psicologia Discursiva no campo da saúde, a partir dos seus objetivos, dos modos peculiares de desenvolver o método, buscando identificar tendências nesse campo de estudo. A descrição dessas tendências permite tanto dar visibilidade a estruturas de argumentação típicas que possam contribuir para a reflexão sobre os caminhos desse campo de estudos, como caracterizar brevemente a área, vislumbrando possíveis desafios aí presentes. 
Por meio dessa análise foi possível caracterizar dois tipos comuns de estudo, que são apresentados a seguir. Juntamente com a descrição da tendência, selecionamos dois estudos representativos dessas tendências para apresentação detalhada da estrutura do artigo (introdução, método e resultados) com o objetivo de caracterizar estes tipos e dar visibilidade ao processo de análise do discurso.

\section{Os repertórios interpretativos em saúde}

Uma primeira tendência é encontrada junto àqueles estudos que buscam a descrição dos repertórios interpretativos sobre determinado aspecto do processo saúde-doença-cuidado. Nessa tendência, encontramos aqueles estudos que investigam o discurso do senso comum sobre fenômenos psicológicos e da saúde, por exemplo, sobre a visão dos idosos sobre a medicação (LUMME-SANDT, HERVOEN, JYLIA, 2000), o campo discursivo da terapia de reposição hormonal (STEPHENS, BUDGE, CARRYER, 2002) e a definição da dieta em pessoas com diabetes (PEEL, PARRY, DOUGLAS, LAWTON, 2005).

Esses estudos são caracterizados pelo compromisso com o tema de pesquisa, pelo reconhecimento da variabilidade da produção discursiva e pela reflexão sobre as implicações para as práticas em saúde. De forma semelhante a preocupações de outras perspectivas no campo das ciências sociais e saúde, esse conjunto de investigações aponta as bases sociais compartilhadas por meio das quais as pessoas dão sentido aos diferentes aspectos do processo saúde-doença-cuidado. Essas pesquisas mostram as possibilidades, bem como as tensões estabelecidas a partir dos diferentes sistemas de significação.

No início da construção da Psicologia Discursiva, na década de noventa, o estudo dos repertórios interpretativos era muito comum, tendo diminuído nos últimos anos. Contudo, no campo da saúde, ele ainda se encontra presente, por vezes, combinado com análises ideológicas e retóricas, complexificando o método utilizado.

Um estudo ilustrativo dessa primeira tendência é o de Stephens, Budge e Carryer (2002), o qual busca identificar e descrever os repertórios interpretativos utilizados por grupos de mulheres de meia-idade na Nova Zelândia para conversar sobre terapia de reposição hormonal, e analisar o uso situado dos mesmos em um contexto específico.

Neste artigo, a revisão da literatura recorta trabalhos anteriores que apontam contradições nas falas das mulheres a respeito da decisão de usar a terapia de reposição hormonal. Assumindo uma perspectiva discursiva, as autoras afirmam que elas são esperadas, pois entendem que as pessoas usam repertórios interpretativos diferentes conforme a situação e os propósitos presentes. A definição do 
objetivo do estudo e o modo de realização da revisão da literatura estão baseados numa perspectiva discursiva e estão voltados para a variabilidade das possibilidades de significação. O compromisso é com o campo temático da pesquisa, mais do que seu modo de investigar. A revisão da literatura recorta as contradições encontradas nos estudos e aponta como a Psicologia Discursiva pode ser útil. A Psicologia Discursiva é aceita e defendida, mas não há uma retórica de sua necessidade. A escolha pelo uso do conceito de repertórios interpretativos incorpora as referências da Psicologia Discursiva enfatizando o aspecto do conteúdo no processo de produção de sentido.

Para alcançar o objetivo, elas entrevistaram e fizeram grupos focais com 80 participantes. Para a análise apresentada no artigo, consideraram as transcrições de 7 grupos focais, sendo três com não usuárias de terapia de reposição hormonal, dois com usuárias e dois grupos mistos.

A análise se dividiu em dois estágios: codificação de trechos em acordo com temas comuns, consensuada entre as três autoras; e análise dos temas comuns em termos do seu significado, buscando padrões mais globais de explicação que constituíram os repertórios interpretativos. Os repertórios foram analisados separadamente e em conjunto.

Os repertórios interpretativos identificados para conversar sobre a menopausa e o uso da terapia de reposição hormonal foram: a mudança ameaçadora, o biomédico, a droga e o natural. Assim, por exemplo, o repertório biomédico possibilitou às mulheres descrever suas experiências com um vocabulário médico. A menopausa foi referida com termos tais como sintomas, doença, hormônios, efeitos colaterais, genes, osteoporose e câncer. Trata-se de um repertório amplamente utilizado, seja por mulheres usuárias ou não da terapia de reposição hormonal. Já o repertório da droga, ele foi usado para a contraposição ao uso de medicação por meio de imagens negativas sobre o uso recreacional de drogas e a dependência química, tais como dependência, síndrome de abstinência, e tomadores de pílulas. Esse repertório era utilizado para construir a terapia de reposição hormonal como uma droga a ser evitada em uma vida saudável, a qual era utilizada apenas por aquelas mulheres que eram fracas e incapazes de manter uma atitude positiva. No artigo, a definição de cada repertório foi acompanhada pela apresentação de trechos ilustrativos de transcrição dos grupos focais.

Além da descrição dos repertórios, as autoras selecionaram um longo trecho de uma conversa para mostrar tais repertórios sendo utilizados em uma situação de interação. Essa análise mostra o caráter negociado, contraditório e contextual do uso dos repertórios.

A análise dos repertórios (em separado e conjuntamente) compreende aspectos do conteúdo e do processo. Contudo, a partir 
da descrição dos repertórios, há uma ênfase no conteúdo. A contribuição da pesquisa está referida, principalmente, ao entendimento dos diferentes significados existentes no interior da temática investigada. A análise do processo se concentrou na análise do uso situado dos repertórios, mostrando a implicação local de cada um deles, sem gerar interpretações mais amplas que caracterizassem diferencialmente os repertórios.

As autoras finalizam o artigo buscando apontar alguns limites do trabalho, relativos à impossibilidade de generalização dos resultados para além dos grupos de mulheres de classe média e sugerem intervenções para facilitar a tomada de decisão em contextos médicos.

Este modo de finalizar o artigo explicita algumas preocupações metodológicas que combinam uma perspectiva discursiva e crítica com modelos mais tradicionais de pesquisa em Psicologia. Assim, metodologicamente, buscam acordar categorias entre as três autoras no primeiro estágio da análise e consideram um limite do artigo a impossibilidade de generalização dos resultados, pois houve um viés na composição da amostra.

Além disso, há uma preocupação com a contribuição da pesquisa para o atendimento das mulheres. As autoras pontuam, criticamente, os problemas decorrentes da hegemonia de um único repertório (repertório biomédico), mas assumem uma postura conciliatória e sugerem um modelo colaborativo de tomada de decisão em saúde, no qual a ampliação do campo discursivo aumentará o grau de satisfação das mulheres.

\section{A construção discursiva do processo saúde-doença-cuidado}

Uma segunda tendência nos estudos inspirados pela Psicologia Discursiva no campo da saúde é caracterizada por aquelas pesquisas que exploram o modo de manejar questões psicológicas e da saúde por meio de diferentes recursos linguísticos, chegando, por vezes, a propor uma releitura discursiva de conceitos psicológicos a elas associados que passam a ser entendidos como práticas do discurso. Esses estudos apresentam forte perspectiva crítica, ênfase na linguagem como ação, análise do conteúdo e do processo, e consideração das implicações morais. ${ }^{2}$

Esses estudos, por exemplo, mostram como se dá a administração das questões normativas nos relatos de reações à infertilidade (KOK, WIDDICOMBE, 2008), a responsabilização-culpabilzação no discurso do veganismo (SNEIJDER, MOLDER, 2004, 2005), a psicologização na constituição conversacional dos distúrbios alimentares (BROOKS, 2009) e a medicalização das descrições de depressão (LAFRANCE, 2007). Numa proposta da revisão dos conceitos na área, 
encontramos estudos que oferecem uma perspectiva discursiva sobre fenômenos tais como o 'pensamento positivo' (WILKINSON, KITZINGER, 2000), a 'negociação sexual' (FRITH; KITZINGER, 2001) e as 'práticas de alimentação' (WIGGINS, POTTER, WILDSMITH, 2001).

Essas pesquisas identificam os mecanismos discursivos presentes nos diversos contextos das práticas de saúde, apontando, teoricamente, os efeitos performáticos da linguagem, e pragmaticamente, como a análise do cuidado em saúde não pode se restringir a perspectivas individualistas e cognitivas. Assim, esses estudos questionam explicações essencialistas sobre tais fenômenos, oferecendo uma descrição inovadora de como são construídos na conversa entre as pessoas, segundo as demandas da interação.

Estudo exemplar dessa tendência é o de Wilkinson e Kitzinger (2000) sobre o 'pensamento positivo', o qual propõe uma abordagem discursiva para a conversa de pacientes com câncer. Inicialmente, as autoras realizam uma leitura crítica dos estudos sobre 'pensamento positivo' na literatura psicossocial em saúde, pautada por um questionamento da construção da evidência nestes estudos (especialmente derivada da aplicação de testes, escalas e questionários padronizados), bem como, pela explicitação de um apagamento do contexto social no qual os pacientes/pesquisados vivem, em que está presente uma forte cultura sustentada pela intensa difusão da literatura de autoajuda.

Esse modo de descrever a revisão da literatura já aponta para uma perspectiva crítica na proposição do estudo. Há uma crítica teórica e metodológica sobre um conceito da literatura e a construção de um novo objeto de investigação. Há uma retórica da desconstrução do passado e da necessidade de um novo futuro nas pesquisas da área. Não se trata, simplesmente, de uma pesquisa sobre as pacientes com câncer, mas da proposição de um novo modo de estudo.

As autoras propõem, então, uma abordagem discursiva sobre o 'pensamento positivo'. Analisando conversas decorrentes da realização de 13 grupos focais sobre a vivência do câncer de mama com 77 mulheres, nos quais as entrevistadas falaram sobre 'pensamento positivo' sem serem questionadas pela entrevistadora, elas identificaram 44 referências sobre esse assunto por meio da busca e seleção de trechos da conversa nos quais estavam presentes as palavras 'positivo' e 'positivamente'.

A análise destes trechos mostrou que o 'pensamento positivo' funciona como uma expressão idiomática. Essa redescrição aponta que o 'pensamento positivo': a) é vago e genérico, não sendo resultado de uma introspecção profunda relatada ao entrevistador; b) é usado especialmente para resumir uma conversa e movê-la para temas menos difíceis ou delicados, tendo uma função importante no processo conversacional e não sendo simplesmente um relato de um 
estado mental; c) não é de um indivíduo, mas do senso comum amplamente compartilhado; e d) é resistente ao questionamento, seja por seu caráter vago, seja por sua forte inserção cultural.

Esta interpretação sobre o 'pensamento positivo' enfatiza uma visão da linguagem como ação. O fenômeno é reconceituado em termos discursivos, deixando de se referir a um processo cognitivo particular para se constituir como um modo de falar em contextos interacionais. A análise sobre o que as pacientes com câncer pensam positivamente mostrou que isso não é expresso de forma clara e quando há referências em diferentes trechos da conversa grupal a esse respeito elas podem ser sobre o câncer e seus efeitos, sobre a recuperação ou sobre outros aspectos da vida que não o câncer. Cada uma destas situações foi explicitada pela apresentação de trechos da transcrição dos grupos focais. Esta imprecisão e variabilidade são esperadas em uma perspectiva discursiva, mas é preocupante se entendida como um estado cognitivo interno.

O principal uso do 'pensamento positivo' ocorre no contexto de conversas sobre problemas, facilitando que as pessoas expressem seu sofrimento e falem de suas dificuldades, podendo ao final 'dar a volta por cima' e aliviar os interlocutores de uma sobrecarga emocional. Exemplo deste uso está no trecho a seguir em que Nettie fala sobre seu sentimento ao receber um segundo diagnóstico de câncer de mama, tendo já passado por uma mastectomia (WILKINSON, KITZINGER, 2000, p.805):

\begin{abstract}
Isso realmente me atingiu, você sabe, me atingiu com uma (risos) pancada e eu ainda pensei de novo, eu tenho que fazer isso, ou, não estarei aqui, e foi simples assim. E como Samantha, eu sou o tipo de pessoa que pensa positivo, e então você tem que, você sabe, seguir em frente (Nettie, TP9, G11).
\end{abstract}

Essa análise sobre ao que se refere o pensamento positivo, bem como, em quais momentos ele é utilizado destaca a atenção metodológica da Psicologia Discursiva não só para o conteúdo, mas também para a função e o processo de uso da linguagem. Neste estudo, a reconceitualização do fenômeno (pensamento positivo) em termos discursivos (expressão idiomática) combinou a análise empírica detalhada do conteúdo com a identificação de uma função mais geral do seu uso.

Outra característica do 'pensamento positivo' apresentada no artigo é que ele é descrito como uma obrigação moral, sendo o uso do imperativo o marcador linguístico dessa ocorrência, tal como, "Você tem que pensar positivo (Mary, TP5, G8)" (WILKINSON, KITZINGER, 2000 , p. 806). O adoecimento se torna então um problema moral. A afirmação do pensamento positivo na conversa entre as participantes da pesquisa parece ser uma forma de proteção contra a acusação de 
que elas causaram o câncer ou que foram displicentes, possibilitando sua progressão.

Devido à forte pressão cultural em torno do 'pensamento positivo', as entrevistadas não o negaram. Contudo, em alguns momentos expressaram certa resistência: afirmando terem 'pensamento positivo', mas apontando seus limites; considerando que isso é dito pelos profissionais de saúde para qualquer uma delas, apesar de todas serem diferentes; e, enfatizando que reconhecem os sintomas e as dificuldades.

Essa análise do modo de expressão de pensamento positivo nas conversas e da identificação da forte prescrição cultural de seu uso se relaciona às preocupações da Psicologia Discursiva decorrentes da visão do ser humano como um ator moral que se constrói nas relações sociais e responde pelos seus relatos. Assim, o uso do pensamento positivo diz respeito às pressões do mundo social.

As autoras finalizam o artigo sintetizando os principais resultados da pesquisa e reafirmando a perspectiva discursiva, a qual gera a necessidade de reconceitualização do status da fala/conversa como interacionalmente produzida e não como relato natural da experiência. Esse modo de concluir o artigo reafirma o compromisso das autoras em produzir uma abordagem discursiva da conversa sobre câncer.

\section{Os desafios da Psicologia Discursiva na saúde}

A análise dessas duas tendências ao se utilizar as constribuições da Psicologia Discursiva no campo dos estudos da Psicologia Social e Saúde mostra como também nesse campo a Psicologia Discursiva permitiu compreender o discurso psicológico do senso comum, bem como releituras de conceitos comuns da psicologia como práticas de discurso.

Dessa forma, essa perspectiva convida os pesquisadores e profissionais do campo da saúde a reconhecer o caráter construído, construtivo e situado da linguagem e sua importância no entendimento e cuidado dos processos de saúde-doença. Ela estimula a valorização e o cuidado dos processos conversacionais presentes nas interações em saúde, considerando-os como aspectos fundamentais de qualquer ação em saúde. Ao mesmo tempo, incita ao reconhecimento do caráter sócio-histórico dos discursos em saúde e das práticas por eles promovidas. Trata-se de um olhar em saúde que abandona a busca por elementos internos aos atores envolvidos nas ações em saúde e se interessa pelos recursos linguísticos disponíveis socialmente para a construção desses atores e suas práticas. 
Além de identificar as contribuições da Psicologia Discursiva no campo dos estudos da Psicologia Social e Saúde, a análise realizada possibilitou reconhecer alguns desafios enfrentados pelos pesquisadores e compartilhados pelos interessados na Psicologia Discursiva. A Psicologia Discursiva está associada a uma forma de fazer pesquisa que tem se constituído como uma alternativa à pesquisa comportamental fortemente associada ao discurso biomédico e predominante na literatura em saúde. Assim, tal como pudemos observar na análise das investigações ilustradas, os pesquisadores desse campo em suas aproximações discursivas enfrentam os seguintes desafios: a hegemonia do discurso biomédico no campo da saúde; as tradições realistas de pesquisa e a lógica tecnicista no cuidado em saúde.

A busca de diálogo interdisciplinar, quimera do campo da saúde, faz esses três aspectos funcionarem como tentação e risco. A sensibilidade às preocupações típicas dos outros pesquisadores e profissionais da área pode levar à captura pelo discurso biomédico hegemônico e suas premissas essencialistas e individualistas, comprometendo as contribuições críticas oriundas da análise do discurso. A Psicologia Discursiva convida a uma consideração dos processos discursivos na constituição das questões em saúde, explicitando a dimensão social presente nas micropolíticas conversacionais.

Da mesma forma, as tradições realistas que orientam muitos pesquisadores da área podem colocar questões metodológicas (relativas a certos critérios de generalização, rigor, etc.) que não se aplicam a esse modo de pensar a produção do conhecimento, desvalorizando-o e descaracterizando-o. A Psicologia Discursiva propõem novos objetos aos pesquisadores da área de saúde, trazendo uma contribuição que não pode ser reduzida a um conjunto de procedimentos analíticos.

A busca em oferecer um melhor cuidado em saúde, se orientada por uma lógica do cuidado pautada pela técnica e pelos protocolos de procedimentos, exige tipos de resultados que não incluem a desconstrução conceitual, a variabilidade discursiva e os efeitos performáticos da linguagem, tais como promovidos pela Psicologia Discursiva.

Apesar de reconhecermos que é possível fazer pesquisa com maior ou menor qualidade, consideramos importante situar a pesquisa como uma prática social, nos afastando de uma possível metodolatria. A abertura e flexibilidade metodológicas permitidas pela Psicologia Discursiva e a Análise do Discurso possibilitam que os pesquisadores produzam diferentes tipos de pesquisa, o que deve estar associado a uma avaliação dos riscos e das implicações do contexto de produção do conhecimento. 


\section{Considerações finais}

Apresentar um panorama geral de uma área tão diversa e dinâmica como a Psicologia Discursiva é uma ousadia. Falar de duas tendências nas pesquisas em saúde é considerá-la, apenas minimamente, em sua diferença. Apesar dos riscos de simplificação e homogeneização presentes nesse tipo de estudo, ele permitiu a identificação da retórica promovida pelas investigações, de suas contribuições específicas, bem como dos desafios enfrentados ao se conduzir pesquisas em Psicologia Discursiva na saúde.

A análise realizada considerou apenas aqueles estudos claramente identificados com a Psicologia Discursiva e a Análise do Discurso a ela associada. É possível, contudo, encontrar outros estudos no campo da saúde pautados por diferentes versões de Análise do Discurso, e que trazem contribuições importantes (MACEDO, 2008). A opção realizada nesse artigo buscou, ao mesmo tempo, considerar a especificidade da Psicologia Discursiva e evitar as polêmicas envolvendo suas relações com a Análise Crítica do Discurso, e suas possíveis conciliações (NOGUEIRA, 2008; WETHERELL, 1998).

Finalizando, consideramos que o vocabulário da Psicologia Discursiva convida a um olhar sobre o mundo, mas pode ser usado situacionalmente, com diferentes funções, conforme as necessidades da interação. É necessário, portanto, que os pesquisadores da área reconheçam os compromissos que possuem e suas consequências, seja no campo da pesquisa em geral, seja especialmente nos contextos de saúde.

\section{Referências}

ANTAKI, C. et al. Discourse Analysis Means Doing Analysis: A Critique of Six Analytic Shortcomings. Discourse analysis online, 2003. Disponível em: <http://extra.shu.ac.uk/daol/articles/open/2002/002/antaki2002002paper.html>. Acesso em: 15 ago. 2008

BROOKS, S. Radio Food Disaster: the conversational constitution of eating disorders in radio phone-ins. Journal of Community $\boldsymbol{\&}$ Applied Social Psychology, New York, v. 19, p. 360-373, 2009. BURR, $V$. An introduction to social constructionism. Londres: Routledge, 1995.

EDLEY, N. Analysing masculinity: interpretative repertoires, ideological dilemmas and subject positions. In: WETHERELL, M.; TAYLOR, S.; YATES, S. (Eds.). Discourse as data: a guide for analysis. London: Sage, 2001, p. 189-228. 
EDWARDS, D. Psicologia Discursiva: teoria da ligação e método com um exemplo. In: INIGUES, L. (Org.) Manual de análise do discurso. Petrópolis: Vozes, 2004, p. 181-205.

EDWARDS, D.; POTTER, J. Discursive psychology. Londres: SAGE, 1992.

FRITH, H.; KITZINGER, C. Reformulating Sexual Script theory: developing a discursive psychology of sexual negotiation. Theory $\boldsymbol{\&}$ Psychology, Londres, v. 11, n. 2, p. 209-232, 2001.

GERGEN, K. J. Realities and relationships. Cambridge: Harvard University Press, 1997.

HEPBURN, A.; WIGGINS. S. Discursive research in practice: new approaches to psychology and interaction. Cambridge: Cambridge University Press, 2007.

HORTON-SALWAY, M. The construction of M.E.: the discursive action model. In: WETHERELL, M.; TAYLOR, S.; YATES, S. (Eds.). Discourse as data: a guide for analysis. Londres: Sage, 2001, pp. 147-188.

INIGUEZ, L. Manual de análise do discurso em ciências sociais. Petrópolis: Editora Vozes, 2004.

KOK, B. C.; WIDDICOMBE, S. 'I really tried': Management of normative issues in accounts of responses to infertility. Social Science \& Medicine, Cambridge, v. 67, n. 7, p. 1083-1093, 2008.

LAFRANCE, M. A bitter pill: a discursive analysis of women's medicalized accounts of depression. Journal of Health Psychology, Londres, v. 12, n. 1, p. 127-140, 2007.

LUMME-SANDT, K.; HERVONEN, A.; JYLHA, M. (2000). Interpretative repertoires of medication among the oldest-old. Social Science \& Medicine, Cambridge, v. 50, n.12, p. 1843-1850, 2000.

MACEDO, L. C. et al . Análise do discurso: uma reflexão para pesquisar em saúde. Interface (Botucatu), Botucatu, v. 12, n. 26, 649-657, 2008.

MURRAY, M.; CHAMBERLAIN, K. Qualitative health psychology. Londres: SAGE, 1999.

NOGUEI RA, C.. Análise(s) do discurso: diferentes concepções na prática de pesquisa em psicologia social. Psicologia: Teoria e Pesquisa, Brasília, v. 24, n. 2, p. 235-242, 2008.

PEEL, E.; PARRY, O.; DOUGLAS, M.; LAWTON J. Taking the biscuit? A discursive approach to managing diet in type 2 Diabetes. Journal of Health Psychology, Londres, v. 10, p. 779-791, 2005.

POTTER, J. Discourse Analysis and Constructionist Approaches: Theoretical Background. In: J. T.E. RICHARDSON (ed.): Handbook of qualitative research methods for psychology and the social sciences. Leicester: BPS Books, 1996, p. 125-140.

POTTER, J. Representing reality. Londres: Sage, 2000. 253 p.

POTTER, J.; WETHERELL, M. Discourse and social psychology. Londres: SAGE, 1997. 
POTTER, J.; WETHERELL, M. Discourse analysis In: SMITH, J. A.; HARRÉ, H.; LANGENHOVE, L. V. (org.) Rethinking methods in Psychology. Londres: SAGE, 1995, p. 80-92.

SARANGI, S. Practising discourse analysis in healthcare settings. In: BOURGEAULT, I.; DINGWALL, R.; DE VRIES, R. (2010). The SAGE Handbook of Qualitative Methods in Health Research. Londres: Sage, 2010, p. 397-415.

SNEIJDER, P.; MOLDER. H. F. M. 'Health should not have to be a problem': talking health and accountability in an internet forum on veganism. Journal of Health Psychology, Londres, v. 9, n. 4, p. 599-616, 2004.

SNEIJDER, P.; MOLDER. H. F. M. Moral logical e logical morality: attributions of morality and blame in online discourse on veganism.

Discourse \& Society, Londres, v. 16, n. 5, p. 675-696, 2005

STEPHENS, C.; BUDGE, R. C.; CARRYER, J. What is this thing called hormone replacement therapy? Discursive construction of medication in situated practice. Qualitative Health Research, Londres, v. 12, n. 3, p. 347-359, 2002.

WIGGINS, S.; POTTER, J. Discursive Psychology. In: WILLIG, C. \& STAINTON-ROGERS, W. The Sage publication handbook of qualitative research in psychology. Londres: Sage, 2008. $631 \mathrm{p}$.

WIGGINS, S.; POTTER, J.; WILDSMITH, A. Eating your words: Discursive Psychology and the reconstruction of eating practices. J ournal of Health Psychology, Londres, v. 6,n. 1, p. 5-15, 2001.

WILKINSON, S.; KITZINGER, C. Thinking differently about thinking positive: a discursive approach to cancer patient's talk. Social Science \& Medicine, Cambridge, v. 50, n. 6, p. 797-811, 2000. WETHERELL, M.; POTTER, J. Discourse Analysis and the identification of interpretative repertoires. In: ANTAKI, C (Ed.), Analysing everyday explanation: a casebook of methods. London: Sage, 1988, p. 168-183.

\section{Endereço para correspondência \\ Emerson F. Rasera \\ Av. Pará, 1720, BI 2C, CEP 38400-902, Uberlândia - MG, Brasil \\ Endereço eletrônico: emersonrasera@gmail.com}

Recebido em: 03/08/2011

Reformulado em: 08/09/2012

Aceito para publicação em: 25/04/2013

Acompanhamento do processo editorial: Ana Maria Lopez Calvo de Feijoo

\footnotetext{
Notas

1 Optamos por realizar uma análise da literatura internacional, devido a sua amplitude e diversidade. Contudo, reconhecemos que no Brasil temos alguns pesquisadores interessados na Psicologia Discursiva. De forma destacada, no campo da Psicologia Social e Saúde, o grupo de pesquisa coordenado pela Profa. Mary Jane Spink (PUC-SP) elaborou uma proposta particular de análise de produção
} 
de sentidos, influenciada pela Psicologia Discursiva, porém com contribuições originais.

2 Nos últimos anos, alguns estudos dessa tendência têm apresentado uma forte influência da Análise da Conversação e seus procedimentos analíticos, o que fortalece de maneira significativa certo empiricismo no campo. Esse fenômeno, por um lado, afasta alguns pesquisadores, dado sua complexa engenharia conceitual e analítica, e por outro, ameaça, aparentemente, o seu caráter crítico e inovador. Trata-se de um processo marcante da área que deverá ser explorado em outro estudo.

3 Agradecimentos: A Profa. Dra. Ana M Jacó Vilela, pela leitura e comentários de versão preliminar. Ao CNPQ pelo apoio financeiro. 